\title{
Immunohistochemical characteristics of neurons in the ganglia of the greater splanchnic nerve of the pig
}

\author{
Jamal Nourinezhad ${ }^{1}$, Piotr Podlasz ${ }^{2}$, Krzysztof Wasowicz ${ }^{2}$ \\ ${ }^{1}$ Division of Anatomy and Embryology, Department of Basic Sciences, Faculty of Veterinary \\ Medicine, Shahid Chamran University of Ahvaz, Ahvaz, Iran \\ ${ }^{2}$ Department of Pathophysiology, Forensic Veterinary Medicine and Administration, \\ Faculty of Veterinary Medicine, University of Warmia and Mazury, Olsztyn, Poland
}

\begin{abstract}
Introduction. Greater splanchnic nerve (GSN) is by far the largest of the splanchnic nerves and connects the paravertebral and prevertebral ganglia to transmit the majority of nociceptive information from the viscera. Despite its importance, the immunohistochemical features of the porcine GSN neurons have not yet been examined. Therefore, the aim of the study was to investigate the neurochemistry of the porcine GSN neurons and to compare their neurochemical coding with those of the paravertebral and prevertebral ganglia.

Material and methods. Four gilts of Large White Polish breed were examined in this study. Antibodies to tyrosine hydroxylase (TH), dopamine $\beta$-hydroxylase (DBH), choline acetyltransferase (ChAT), neuropeptide $\mathrm{Y}$ (NPY), vasoactive intestinal polypeptide (VIP), somatostatin (SOM), galanin (GAL), methionine-enkephalin (MET), calcitonin gene-related peptide (CGRP), and substance P (SP) were used for immunohistochemical detection of classical neurotransmitters marker enzymes and neuropeptides in neuronal cell bodies of the GSN. Results. Double-labeling immunofluorescence revealed that virtually all GSN neurons exhibited the presence of catecholamine-synthesizing enzymes (TH/DBH-positive) and subpopulations of neurons contained immunoreactivity to NPY, VIP, SOM, GAL and MET. However, CGRP and SP-immunoreactivity were not observed in neuronal somata.

Conclusions. Our data strongly suggest that the general immunohistochemical characterization of ganglion cells in the porcine greater splanchnic nerve is similar to that of the prevertebral ganglia (e.g. celiacomesenteric ganglion). (Folia Histochemica et Cytobiologica 2017, Vol. 55, No. 4, 221-229)
\end{abstract}

Key words: greater splanchnic nerve; neurons; neurotransmitters; pig; immunohistochemistry

\section{Introduction}

The myelinated presynaptic sympathetic axons that pass through the paravertebral ganglia and continue to the prevertebral ganglia form a major portion of the splanchnic nerves in the domestic animals [1]. The

\footnotetext{
Correspondence address: Prof. K. Wasowicz

Department of Pathophysiology, Forensic Veterinary

Medicine and Administration

Faculty of Veterinary Medicine, University of Warmia

and Mazury

13 Oczapowskiego St., 10-957 Olsztyn, Poland

tel.: +48 895233733 , fax: +48 895234986

e-mail:wasowicz@uwm.edu.pl
}

porcine thoracic splanchnic nerves are the splanchnic nerves that arise from thoracic paravertebral ganglia inside the thoracic cavity and divide into three main categories, namely, the greater (major), lesser (minor), and least (imus) with regard to their level and dimensions [2]. The porcine greater splanchnic nerve (nervus splanchnicus major) is by far the largest of the splanchnic nerves and is frequently larger than postdiaphragmatic sympathetic trunk and terminates essentially in the adrenal and celiac mesenteric plexuses [3]. Therefore, these nerves connect the paravertebral and prevertebral ganglia. In addition, the celiac ganglia are functionally related to the splanchnic nerves [4]. The splanchnic nerves contain the visceral efferent fibers but also pain-conducting visceral afferent fibers $[5,6]$ and transmit the majority of nociceptive information 
from the viscera. Clinically, splanchnic nerve block may provide relief of pain in a subset of patients who fail to obtain relief from celiac plexus block [7].

The presence of ganglia in the human greater splanchnic nerve was histologically investigated $[8,9]$. The role of neuropeptides as putative neurotransmitters has become an important consideration in the study of nervous system functions. Different neuropeptides have previously been reported to exist in neurons of paravertebral and prevertebral ganglia in various mammalian species, including vasoactive intestinal polypeptide (VIP) in the pig [10, 11], cat [12], newborn and young mice [13], sheep [14], rat neonates and pups [15], and humans [16]; encephalin (MEAGL) in the pig [10,11]; neuropeptide Y (NPY) in the pig [10,11], cat [12], newborn and young mice [13], sheep [14], rat neonates and pups [15], and humans [16]; substance P (SP) in the pig [10,11], cat [12], sheep [14], and humans [16]; calcitonin gene-related peptide (CGRP) in the pig [10,11], cat [12], newborn and young mice [13], sheep [14], and rat neonates and pups [15]; galanin (GAL) in the newborn and very young mice [13], sheep [14], rat neonates and pups [15], and pig [17]; somatostatin (SOM) in the pig [10, 11], cat [12], rat neonates and pups [15], humans [16], and newborn and young mice [18]. In this study, attention has been focused on the neurochemical characteristics of neurons in the porcine greater splanchnic nerve, because until now the porcine GSN neurons have yet not been characterized by immunohistochemistry. Additionally, with regard to neural connections of the greater splanchnic nerve, we decided to compare neurotransmitter features of those neurons with neurons in paravertebral and prevertebral ganglia. Pig is also widely used in neuroscience as a model because of their anatomical and physiological similarities to humans [19]. Therefore, the present study was performed by using double-immunocytochemistry method for distinguishing the occurrence and pattern of colocalization of neurotransmitters such as tyrosine hydroxylase (TH), dopamine $\beta$-hydroxylase (DBH) as markers of catecholaminergic neurons, and choline acetyltransferase (ChAT) as a marker of cholinergic neurons as well as neuropeptides, namely neuropeptide Y (NPY), vasoactive intestinal polypeptide (VIP), somatostatin (SOM), galanin (GAL), methionine-enkephalin (MET), calcitonin gene-related peptide (CGRP), and substance P (SP).

\section{Material and methods}

Four gilts of Large White Polish breed (ca. $10 \mathrm{~kg}$ of body weight) were purchased from a commercial farm. All handling of experimental animals followed rules of animal experimentation (NIH publications No. 80-23, Rev. 1987) and specific national laws on animal experimentation.

The animals were deeply anaesthetized with pentobarbital (Thiopental, Sandoz GmbH, Vienna, Austria, $30 \mathrm{mg} / \mathrm{kg}$ of body weight, i.v.), and subsequently perfused transcardially with $4 \%$ paraformaldehyde in $0.1 \mathrm{M}$ phosphate buffer (pH 7.4). The thoracic sympathetic trunks and ganglia were gently dissected to remove the greater splanchnic nerves which were formed by roots derived from the last several thoracic ganglia and interganglionic branches.

The nerves were postfixed in the same fixative for $30 \mathrm{~min}$, and transferred to $18 \%$ sucrose in $0.1 \mathrm{M}$ phosphate buffer with $0.05 \% \mathrm{NaN}_{3}$ for storage at $+4^{\circ} \mathrm{C}$ until processing. Cryostat sections $15 \mu \mathrm{m}$ thick were put on chrome alum-gelatine-coated slides, dried for $20 \mathrm{~min}$ at room temperature (RT) and stored desiccated at $-70^{\circ} \mathrm{C}$. For finding neuronal cell bodies in the greater splanchnic nerve, some slides were stained with $1 \%$ thionine in water. For immunohistochemistry, sections were re-hydrated in phosphate-buffered saline (PBS, pH 7.4) and processed for indirect immunofluorescence as described previously [20]. The data of antibodies used are listed in Table 1. Primary antibodies were used in following combinations: TH/DBH, TH/ChAT, TH and DBH/NPY, TH and ChAT/VIP, TH/GAL, TH/MET, DBH/ /SOM, TH/SP and TH/CGRP.

The slides were observed and images were captured by using a laser scanning confocal microscope (MRA-2, Bio Rad, Hemal Hempstead, UK) or fluorescence microscope (Axiophot, Zeiss, Jena, Germany) equipped with the appropriate filter for Alexa Fluro and a digital camera (Olympus, C-2020Z, Japan).

\section{Results}

The neuronal cell bodies were localized throughout the porcine GSN and the distribution of neurons did not show a topographical arrangement (Fig. 1).

Virtually all of cell bodies were TH-positive and exhibited also immunoreactivity to DBH (Fig. 2). Intensity of immunostaining of TH-immunoreactive (IR) neurons varied. Approximately $30 \%$ of them showed strong TH-immunoreactivity and they were mainly located at the periphery of the ganglia while the rest $(70 \%)$ of perikarya displayed moderate TH-immunoreactivity. Double-labeling immunostaining revealed that $\mathrm{DBH}$-positive neurons were ChAT-negative (Fig. 3a, b).

A great number of evenly distributed NPY-IR neurons were present in the GSN neurons. They displayed immunoreactivity to $\mathrm{TH}$ (Fig. 3c, d), whereas only single NPY-IR neurons immunonegative for DBH were found in the ganglia (Fig. 3e, f).

Single VIP-positive neurons were visible in ganglia in the different areas. They were often TH-negative; 
Table 1. Characteristics of antibodies used in this study

\begin{tabular}{|c|c|c|c|c|}
\hline Antigen & Species & Code & Dilution & Supplier \\
\hline \multicolumn{5}{|l|}{ Primary antibodies } \\
\hline $\mathrm{TH}$ & Mouse & 729928 & $1: 50$ & Sigma \\
\hline ChAT & Goat & $\mathrm{AB} 144 \mathrm{P}$ & 1:100 & Millipore \\
\hline VIP & Rabbit & AB22736 & $1: 5000$ & Abcam \\
\hline NPY & Rabbit & NA1233 & $1: 5000$ & Biomol \\
\hline MEAGAL & Rabbit & RPN1562 & 1:600 & Amersham \\
\hline SOM & Rat & $\mathrm{AB} 22682$ & $1: 50$ & Chemicon \\
\hline SP & Rabbit & $8450-050$ & 1:600 & Sigma \\
\hline CGRP & Rabbit & 11535 & $1: 2000$ & Cappel \\
\hline $\mathrm{DBH}$ & Rabbit & DZ 1020 & $1: 500$ & Biomol \\
\hline GAL & Rabbit & RIN71533 & $1: 2000$ & Peninsula \\
\hline \multicolumn{5}{|l|}{ Secondary antibodies } \\
\hline Alexa Fluor ${ }^{\circledast} 488$ anti-rabbit IgG & Donkey & A-21206 & $1: 500$ & Invitrogen \\
\hline Alexa Fluor ${ }^{\circledast} 488$ anti-mouse IgG & Goat & A-11001 & $1: 500$ & Invitrogen \\
\hline Alexa Fluor ${ }^{\circledR} 546$ anti-goat IgG & Donkey & A-11056 & $1: 500$ & Invitrogen \\
\hline Alexa Fluor $^{\circledR} 546$ anti-rabbit IgG & Goat & A-11010 & $1: 500$ & Invitrogen \\
\hline Alexa Fluor ${ }^{\circledR} 488$ anti-rabbit IgG & Goat & A-11008 & $1: 500$ & Invitrogen \\
\hline
\end{tabular}

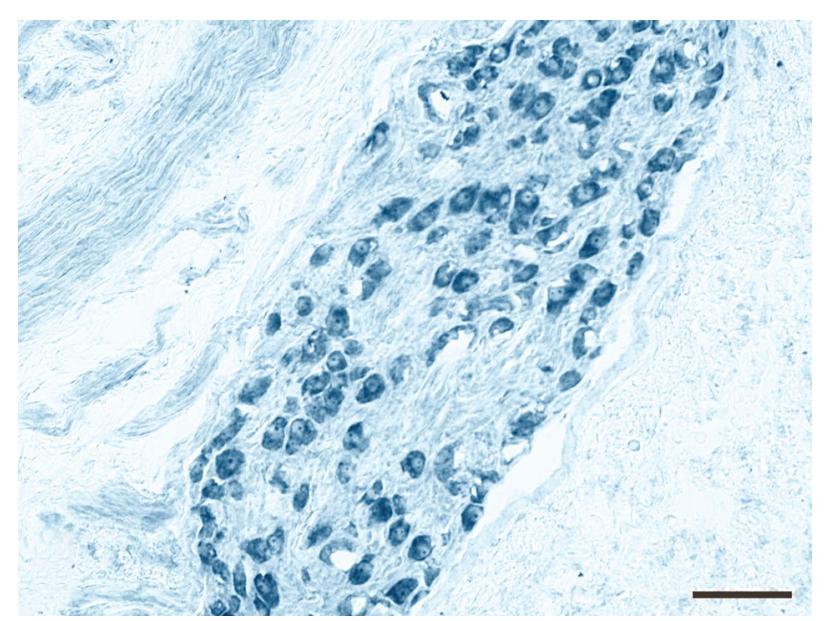

Figure 1. Light photomicrograph of the appearance of the ganglia in the porcine greater splanchnic nerve (GSN) stained with thionine. Scale bar: $200 \mu \mathrm{m}$.

however, single neurons were TH-positive (Fig. 4a, b). They exhibited also ChAT-immunoreactivity (Fig. 4c, d).

Single neural cell bodies were GAL-positive (Fig. 4e, f). They usually showed TH-immunoreactivity and were located in different areas. Only single GAL-positive neurons did not express TH-immunoreactivity (Fig. 5a, b).

Big clusters containing very small cells were noted occasionally. They displayed GAL-immunoreactivity and were TH-IR (data not shown). Probably they represented chromaffin cells.

A few neurons were MET-IR. They often expressed TH-immunoreactivity (Fig. 5c, d). Only single neurons were not TH-IR.

Immunoreactivity to SOM was displayed by single neurons throughout the ganglia. They were also DBH-IR (Fig. 5e, f).

In all examined ganglia, immunoreactivity to SP and CGRP was not detected in the neurons.

\section{Discussion}

The present study demonstrates the presence of neurons in the ganglia of the porcine greater splanchnic nerve. The vast majority of neurons expressed $\mathrm{TH}$ and DBH-immunoreactivity. It means that these cell bodies are noradrenergic. This is in agreement with previously obtained data on the paravartebral ganglia of the rat neonates and pups [15], newborn and young mice $[13,18]$, newborn and young mice and rats [21], and on the prevertebral ganglia of the pig [17]. The remaining small population of neurons in the greater splanchnic nerve did not express $\mathrm{TH}$ or DBH. On the other hand, we did not detect any neurons immunoreactive to ChAT. Therefore, it is possible that the TH- or DBH-negative neurons can be regarded as non-noradrenergic/non-cholinergic, which is also consistent with results of other studies 

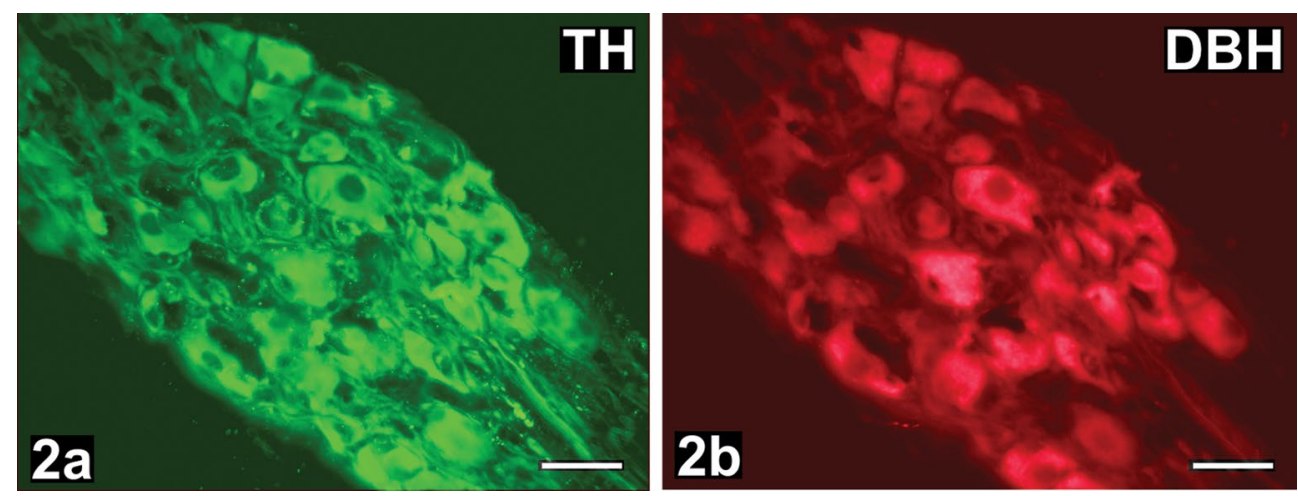

Figure 2. Double-labeling of sections from the porcine greater splanchnic nerve (GSN) immunostained for (a) tyrosine hydroxylase (TH), and (b) dopamine B-hydroxylase (DBH). Neurons which stained for TH were simultaneously DBH-positive (arrow). Scale bar: $50 \mu \mathrm{m}$.
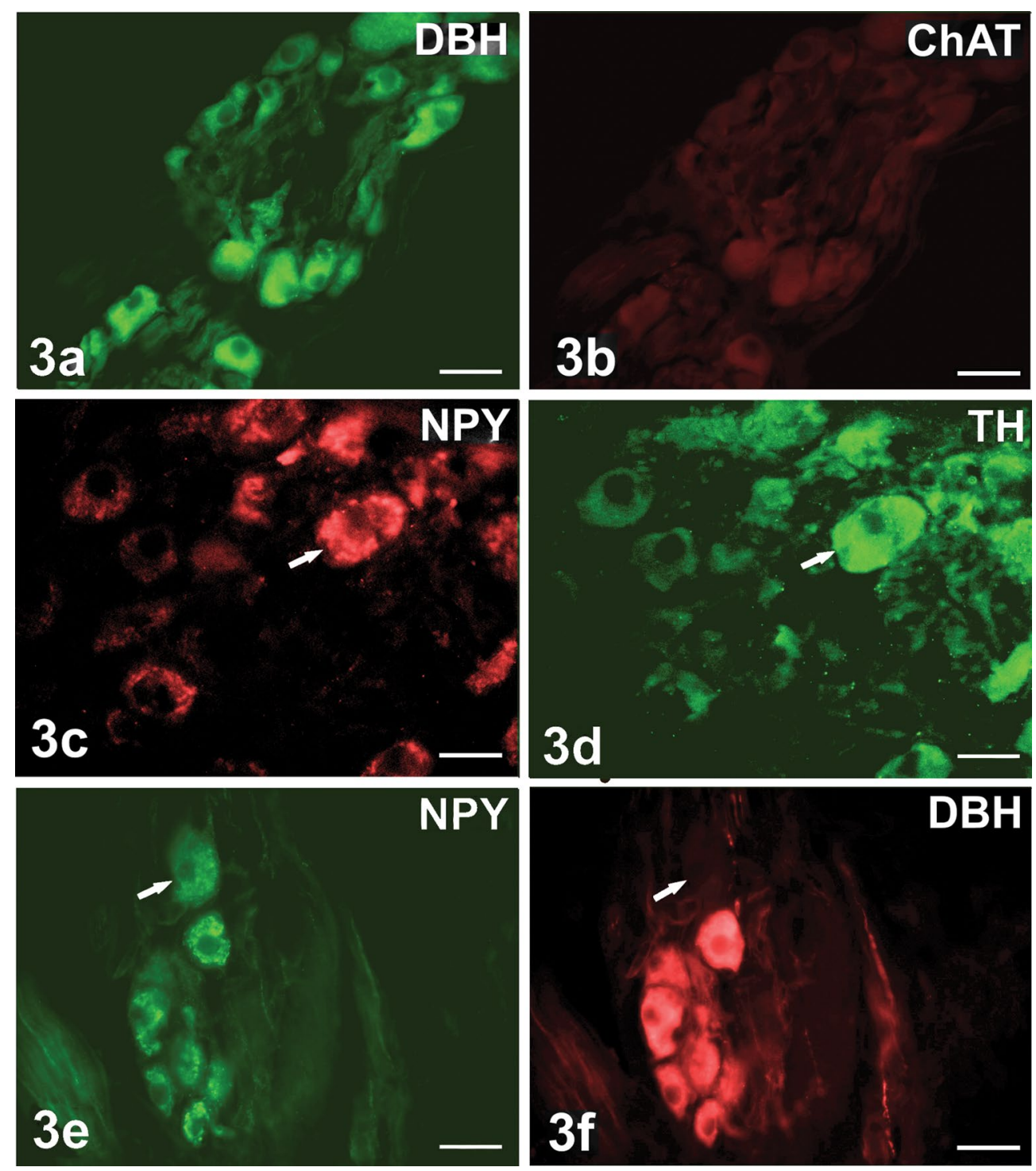

Figure 3. Double-labeling of sections from the porcine greater splanchnic nerve (GSN) immunostained for (a) dopamine B-hydroxylase (DBH) and (b) choline acetyltransferase (ChAT), (c) neuropeptide Y (NPY) and (d) tyrosine hydroxylase (TH), (e) NPY and (f) DBH. All neurons which stained for DBH were ChAT-negative and NPY-positive. All neurons which stained for TH were NPY-positive (arrows). Scale bar: $50 \mu \mathrm{m}$. 

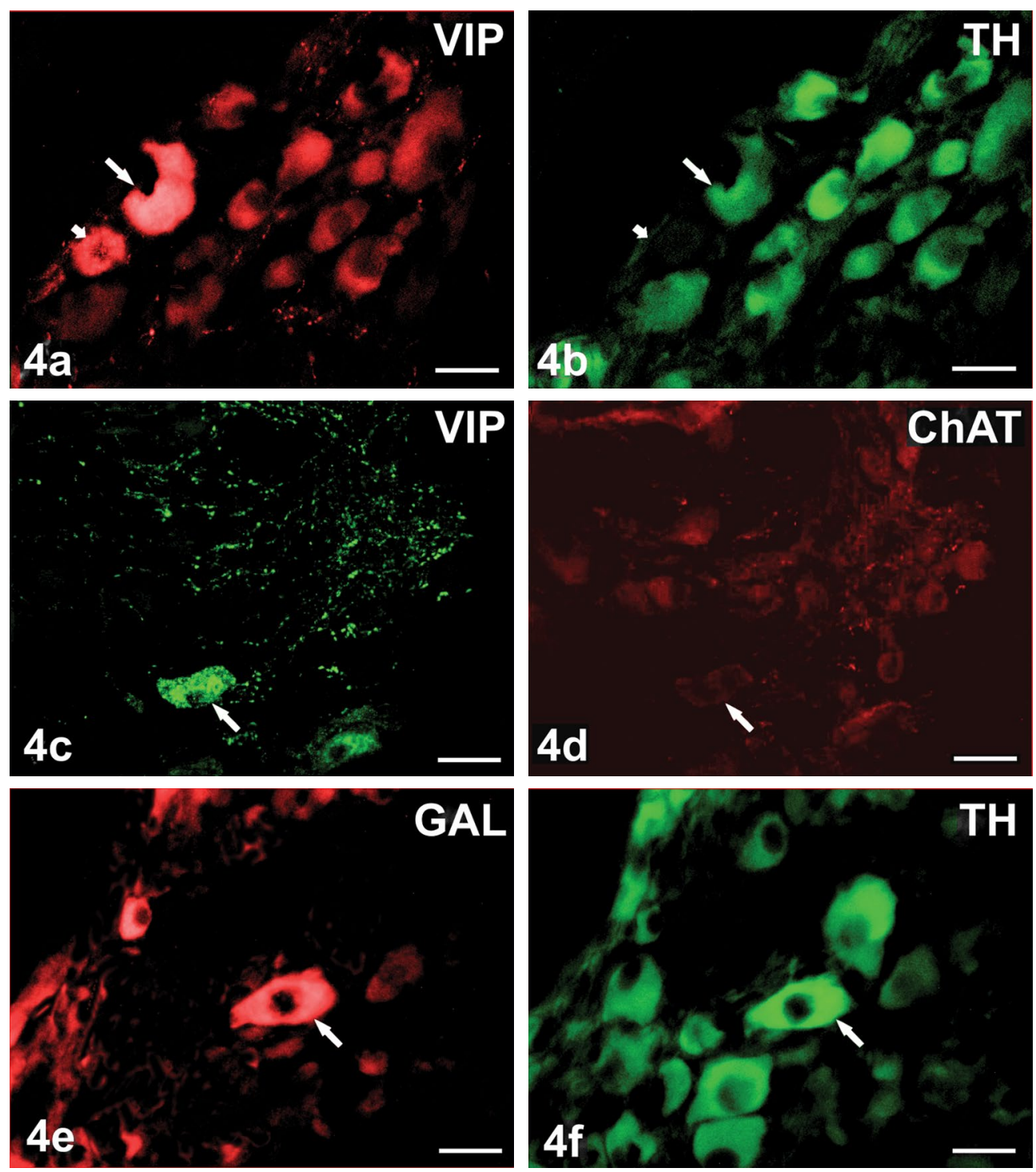

Figure 4. Double-labeling of sections from the porcine greater splanchnic nerve (GSN) immunostained for (a) vasoactive intestinal polypeptide (VIP) and (b) tyrosine hydroxylase (TH), (c) VIP and (d) choline acetyltransferase (ChAT), (e) galanin (GAL) and (f) tyrosine hydroxylase (TH). All neurons which stained for TH were VIP- and GAL-positive. Neurons, which stained for ChAT were negative but were VIP-positive (arrows). Scale bar: $50 \mu \mathrm{m}$.

on the neurons of the sympathetic ganglia in sheep [14] or pig [17].

NPY was widely distributed in neurons throughout the porcine greater splanchnic nerve ganglia. NPY is a major co-transmitter in the sympathetic ganglia, which is in accordance with immunohistochemistry reports in neurons of the sympathetic ganglia in pig [11], newborn and young mice [13], sheep [14], rat neonates and pups [15], and humans [16]. Previous studies described various size of the population of NPY-IR neurons in sympathetic ganglia in different mammals: $80 \%$ in the porcine celiac-superior mesenteric ganglia (CSMG) [17], 80-85\% in the superior cervical ganglion (SCG) and middle cervical ganglion (MCG) of the cats and dogs [22], 40-60\% in porcine stellate ganglion (SG) [10], 5-10\% in porcine thoracolumbar ganglia [11]. There was an increase in the proportion of NPY-positive neurons during postnatal period from birth to $60 \mathrm{dpp}$ of rats and mice $[13,15$, $18,21]$. Thus, our findings are in accord with the results of previous studies describing the population of NPY-positive neurons in the postnatal period in rat and mouse [13, 15, 18, 21], dog and cat [22], and pig [17].

In the noradrenergic neurons, NPY are often co-localized with catecholamine-synthesizing enzymes 

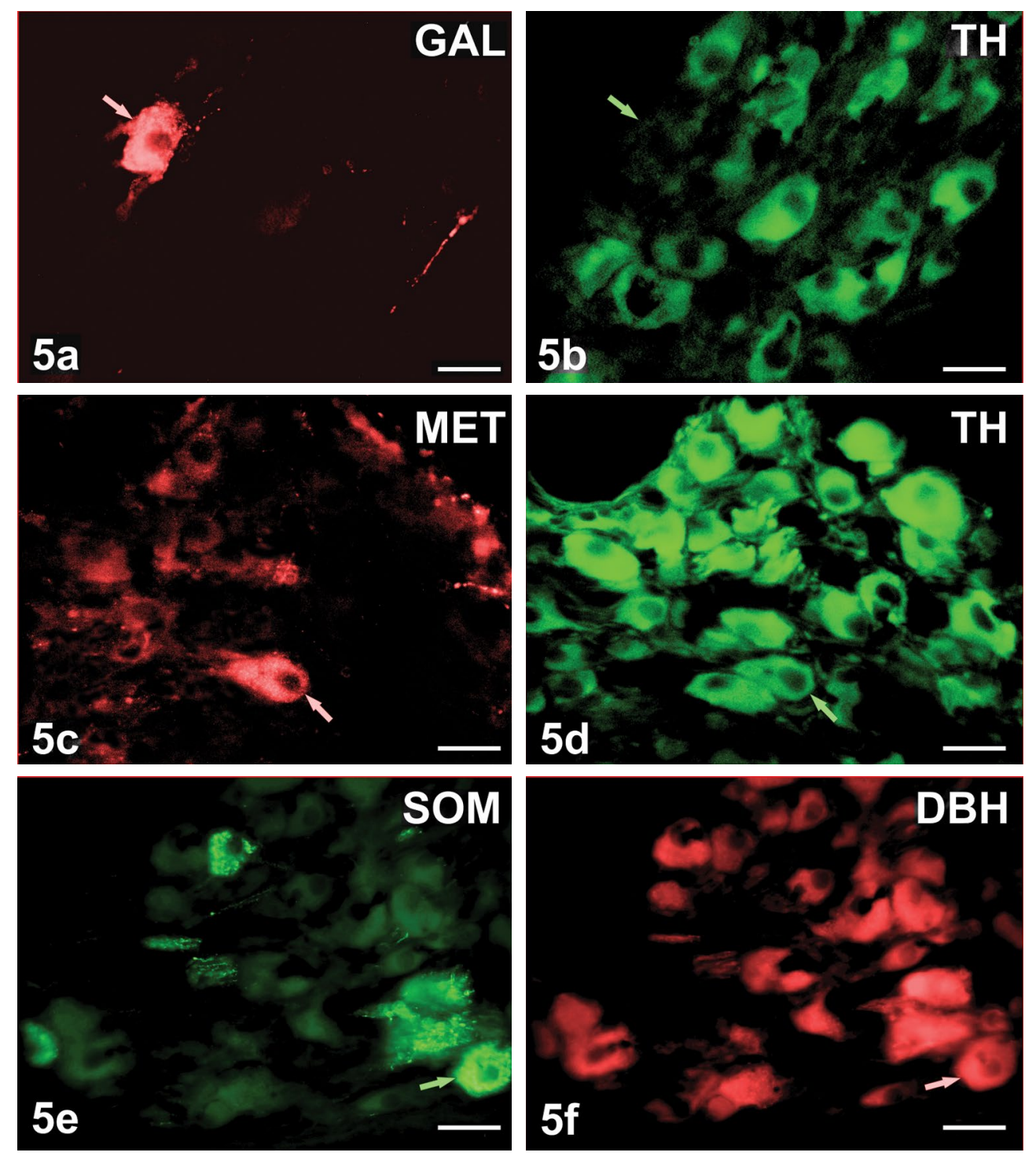

Figure 5. Double-labeling of sections from the porcine greater splanchnic nerve (GSN) immunostained for (a) galanin (GAL) and (b) tyrosine hydroxylase (TH), (c) methionine-enkephalin (MET) and (d) TH, (e) somatostatin (SOM) and (f) dopamine B-hydroxylase (DBH). Neurons which stained for TH were Gal-negative but MET-positive. Neurons which stained for DBH were SOM-positive (arrows). Scale bar: $50 \mu \mathrm{m}$.

(TH/DBH). In the present study, all neurons which showed TH-immunoreactivity were also NPY-IR, while in the neurons of the porcine superior cervical ganglion (SCG), only small population of nerve cells contained both TH and NPY [23]. In our study, only single NPY-IR neurons were immunonegative for $\mathrm{DBH}$. Such result was reported previously in the ovine MCG and in the SG of newborn and young mice and rats $[14,21]$.

VIP, a neurotransmitter characteristic of cholinergic neurons was also found in the neurons of the porcine greater splanchnic nerve. The population of VIP-IR perikarya found in sympathetic ganglia varies between species. Single neurons exist in the ganglia of the porcine lumbar [24], stellate [10, 24], celiac-superior mesenteric ganglia [18]. In the porcine thoracic ganglia several clusters of 4 or more VIP-IR cells were described [24], and a small number of VIP-IR ganglionic cells in the cat superior mesenteric ganglion [12] as well as the SG of newborn and young mice and rats were observed [21]. In contrast, numerous cell were present in the canine SG and MCG [22], while VIPIR neurons were not demonstrated in the ovine MCG [14] and porcine SCG [23, 25]. In the present study, single neurons displayed immunoreactivity to VIP.

In this study, single VIP-IR neurons were TH-negative and ChAT-negative, whereas TH-immunoreactivity in VIP-immunoreactive neurons of the human 
lumbar ganglia [26] and porcine SCG [23, 25] were not identified. The coexistence of DBH- and VIP-IR neurons was not identified in the paravertebral and prevertebral sympathetic ganglia of the cat [27], while the colocalization of DBH- and VIP-immunoreactivity was indicated only in neurons of thoracic ganglia in the pig [24]. In addition, some VIP-IR neurons were also TH-IR in the SG of newborn and young mice and rats [21] and most of the VIP-IR cells contained ChAT in the SG of newborn and young mice and rats [21]. On the other hand, the proportion of neurons expressing VIP- and TH-immunoreactivity as well as ChAT-immunoreactivity in the SG of newborn and young mice and rats decreased during postnatal development [21] because, according to Masliukov and Timmermans [21], the development of different subpopulations of sympathetic neurons and expression of different combinations of neurotransmitters may be dependent on different combinations of trophic factors.

In this study, GAL was found only in single neurons of the porcine GSN neurons and they expressed strong immunoreactivity to galanin. In the SG of cat, a large number of GAL-IR neurons were present [28], whereas in the SG of newborn and young mice and rats less than $1 \%$ of GAL-IR neurons were reported [21]. By contrast, immunoreactivity to GAL was not found in the SG of newborn and young mice [13] and in the SG of newborn and young mice and rats [21], in the ovine MCG [14], and in the porcine SCG [25]. No GAL-immunoreactive nerve cells were found in the thoracolumbar [11] and stellate ganglia of the pig [10], while in the porcine CSMG only solitary GAL-IR neurons were detected [17]. In our study, double-immunofluorescence revealed that only single GAL-positive neurons did not show TH-IR, indicating that these cells are non-noradrenergic, whereas virtually all of the GAL-IR cell bodies in the inferior mesenteric ganglion of pig [29] did not show immunoreactivity to $\mathrm{TH}$ or only small population of the porcine SCG contained TH and GAL [23].

The presence of the chromaffin cells in the ganglia of the porcine GSN seems to be logical because these cells originate from the neural crest and migrate to the area adjacent to the sympathetic ganglia (paraganglia) and to the medulla of the adrenal glands [30]. Possibly during their immigration in parental development, the chromaffin cells remain near to the ganglia of the GSN before populating the prevertebral ganglia and the medulla of the adrenal glands, because the GSN terminates primarily in adrenal plexus and celiacomesenteric plexus and ganglia [3].

Enkephalins have been shown to inhibit noradrenaline release from sympathetic nerve terminals. Previous studies indicated also that approximately $20-30 \%$ of neurons of the pig SG [11], and less than 5\% in the porcine celiac-superior mesenteric ganglia [17] were immunoreactive to Met-enkephalin-Arg-Gly-Leu (MEAGL), whereas Lakomy et al. [11] described single MEAGL-positive neurons in the thoracic ganglia and more numerous in lumbar ganglia. In the present investigation, MET-immunoreactivity was localized in a few neurons of the porcine greater splanchnic nerve.

Numerous SOM-IR neurons were found to be present in the cat SMG [12]. However, in the pig, only a small number of such neurons were reported in the CSMG [17] and SG [11]. On the contrary, neurons of the SG of newborn and young mice $[13,18]$ and porcine SCG [24] did not exhibit immunoreactivity to SOM. Available papers did not report the presence of SOM in the thoracolumbar paravertebral ganglia of the pig [11]. In the present study, the greater splanchnic nerve ganglia contained only single SOM-positive neurons.

In the current study, neurons immunoreactive to SP or CGRP were not noted. These results differed from the previous findings which reported the presence of CGRP-IR neurons in SG of the cat [31], in the human paravertebral ganglia [32] and in the SG of pig $[17,33]$ as well as the existence of SP-IR neurons in the SG of dog [22], cat [31], and pig [33].

The perspective gained by the review of the developmental anatomy of the GSN may help to clarify why neurons in the ganglia of the GSN are immunohistochemically close to the prevertebral ganglia (e.g. celiacomesenteric ganglia). Greater splanchnic nerves derive from the caudal thoracic paravertebral ganglia during prenatal period [33], and the ganglion cells in the splanchnic nerves represent cells that in their displacement from the primordia of sympathetic trunk ganglia do not reach the primordia of prevertebral ganglia. However, the primordia of prevertebral ganglia aggregate in the paths of the splanchnic nerves and differentiate into ganglion cells [35]. Structural changes [34] such as expression of catecholaminergic transmitter and neuropeptide phenotype in sympathetic neurons also occur during prenatal development and the development of different subpopulations of sympathetic neurons and expression of different combinations of neurotransmitters may be also dependent on different combinations of trophic factors [21].

In summary, with regard to the presence of noradrenergic (TH/DBH-positive) neurons as well as NPY-, VIP-, GAL-, MET-, and SOM-positive neurons in the ganglia of porcine greater splanchnic nerve our data strongly suggest that the general immunohistochemical characterization of GSN neurons resembles that of the prevertebral ganglia. 


\section{Acknowledgements}

The authors would like to thank Ms. Maria Marczak, Mrs. Grazyna Greniuk, and Mr. Aleksander Penskowski for their skillful technical assistances. The appreciation of the authors is extended to Prof. Dr. Miroslav Lakomy for his helpful suggestions and encouragements to conduct experiment. This study was supported by Research Affairs of Shahid Chamran University of Ahvaz.

\section{References}

1. Jenkins TW. Functional Mammalian Neuroanatomy. 2nd ed. Lea and Febiger, Philadelphia 1978: 150-159.

2. Orhan O, Duzler A. Anatomy of the thoracic splanchnic nerves in pigs. Vet Res Commun. 2007; 31(3): 237-243, doi 10.1007/s11259-006-3436-8, indexed in Pubmed: 17216312.

3. Goshal NG, Getty R. Postdiaphragmatic disposition of the pars sympathica and major autonomic ganglia of the domestic pig (Sus scrofa domesticus). Anat Anz. 1969; 125(4): 400-411, indexed in Pubmed: 5391726.

4. Kuntz A. The structural organization of the celiac ganglia. J Comp Neurol. 1938; 69(1): 1-12, doi: 10.1002/cne.900690102.

5. Kuo D, Krauthamer G. Paravertebral origin of postganglionic sympathetic fibers in the major splanchnic and distal coeliac nerves as demonstrated by horseradish peroxidase (HRP) retrograde transport method. J Aut Nerv Syst. 1981; 4(1): 25-32, doi: 10.1016/0165-1838(81)90004-7.

6. Naidoo N, Partab P, Pather N, et al. Thoracic splanchnic nerves: implications for splanchnic denervation. J Anat. 2001; 199(Pt 5): 585-590, indexed in Pubmed: 11760889.

7. Abram SE, Boas RM. Sympathetic and visceral nerve blocks. In: Benumof JL. ed. Clinical Procedures in Anesthesia and Intensive Care. Lippincott Williams and Wilkins 1992.

8. Kuntz A. Distribution and relationships of sympathetic ganglia in the splanchnic region. Trans Am Neurol Assoc. 1955; 80: 88-91, indexed in Pubmed: 13312010.

9. Woźniak W, Bruska M. Fine structure and myelination of the greater splanchnic nerves in human fetuses. Folia Morphol (Warsz). 1986; 45(3): 192-205, indexed in Pubmed: 3583120.

10. Häppölä O, Lakomy M, Majewski M, et al. Distribution of neuropeptides in the porcine stellate ganglion. Cell Tissue Res. 1993; 274(1): 181-187, indexed in Pubmed: 7694801.

11. Lakomy M, Häppölä $\mathrm{O}$, Kaleczyc J, et al. Immunohistochemical localization of neuropeptides in the porcine thoraco-lumbar paravertebral ganglia. Anat Histol Embryol. 1994; 23(1): 12-20, indexed in Pubmed: 7943753.

12. Stoyanova I, Scheuermann DW, Chouchkov C. Neurochemical features of feline superior mesenteric ganglion. Ital J Anat Embryol. 1998; 103(1): 35-43, indexed in Pubmed: 9602548.

13. Masliukov PM, Shilkin VV, Timmermans JP. Immunocytochemical characteristic of neurons of the mouse truncus sympaticus stellate ganglion in postnatal ontogenesis. Morfologiia. 2005; 128(5): 41-44, indexed in Pubmed: 16669243.

14. Arciszewski MB, Wasowicz K. Neurochemical properties of the middle cervical ganglion in the sheep. Ann Anat. 2006; 188(1): 75-83, doi: 10.1016/j.aanat.2005.09.008, indexed in Pubmed: 16447916.
15. Maslyukov PM, Nozdrachev AD, Timmermans JP. Age-related characteristics of the neurotransmitter composition of neurons in the stellate ganglion. Neurosci Behav Physiol. 2007; 37(4): 349-353, doi: 10.1007/s11055-007-0020-9, indexed in Pubmed: 17457529.

16. Baffi J, Görcs T, Slowik F, et al. Neuropeptides in the human superior cervical ganglion. Brain Res. 1992; 570(1-2): 272-278, doi: 10.1016/0006-8993(92)90591-v, indexed in Pubmed: 1352173 .

17. Lakomy M, Häppölä $\mathrm{O}$, Majewski $\mathrm{M}$, et al. Neuropeptides in the porcine coeliac-superior mesenteric ganglion. Folia Histochem Cytobiol. 1993; 31(4): 181-191, indexed in Pubmed: 7907996.

18. Maslyukov PM, Shilkin VV, Timmermans JP. Immunocytochemical characteristics of neurons in the stellate ganglion of the sympathetic trunk in mice during postnatal ontogenesis. Neurosci Behav Physiol. 2006; 36(8): 851-855, doi: 10.1007/ /s11055-006-0097-6, indexed in Pubmed: 16964463.

19. Bassols A, Costa C, Eckersall PD, et al. The pig as an animal model for human pathologies: a proteomics perspective. Proteomics Clin Appl. 2014; 8(9-10): 715-731, doi: 10.1002/ /prca.201300099, indexed in Pubmed: 25092613.

20. Nourinezhad J, Wasowicz K, Bukowski R, et al. Analysis of the chemical coding of neurons in the intermediate thoracic ganglion of the pig. Pol J Vet Sci. 2010; 13(3): 537-543, indexed in Pubmed: 21033570.

21. Masliukov PM, Timmermans JP. Immunocytochemical properties of stellate ganglion neurons during early postnatal development. Histochem Cell Biol. 2004; 122(3): 201-209, doi: 10.1007/s00418-004-0692-y, indexed in Pubmed: 15338227.

22. Darvesh S, Nance DM, Hopkins DA, et al. Distribution of neuropeptide-like immunoreactivity in intact and chronically decentralized middle cervical and stellate ganglia of dogs. J Auton Nerv Syst. 1987; 21(2-3): 167-180, doi: 10.1016/01651838(87)90019-1, indexed in Pubmed: 2453549.

23. Wojtkiewicz J, Juranek JK, Kowalski I, et al. Immunohistochemical characterization of superior cervical ganglion neurons supplying porcine parotid salivary gland. Neurosci Lett. 2011; 500(1): 57-62, doi: 10.1016/j.neulet.2011.05.242, indexed in Pubmed: 21683765.

24. Hill EL, Elde R. Vasoactive intestinal peptide distribution and colocalization with dopamine-beta-hydroxylase in sympathetic chain ganglia of pig. J Auton Nerv Syst. 1989; 27(3): 229-239, doi: 10.1016/0165-1838(89)90116-1, indexed in Pubmed: 2794349.

25. Juranek JK, Wojtkiewicz JA. Origins and neurochemical complexity of preganglionic neurons supplying the superior cervical ganglion in the domestic pig. J Mol Neurosci. 2015; 55(2): 297-304, doi: 10.1007/s12031-014-0321-8, indexed in Pubmed: 24854048.

26. Järvi R, Helen P, Hervonen A, et al. Vasoactive intestinal peptide (VIP)-like immunoreactivity in the human sympathetic ganglia. Histochemistry. 1989; 90(5): 347-351, indexed in Pubmed: 2565893.

27. Heym C, Reinecke M, Weihe E, et al. Dopamine-beta-hydroxylase-, neurotensin-, substance $\mathrm{P}$-, vasoactive intestinal polypeptide- and enkephalin-immunohistochemistry of paravertebral and prevertebral ganglia in the cat. Cell Tissue Res. 1984; 235(2): 411-418, doi: 10.1007/bf00217867, indexed in Pubmed: 6200232 . 
28. Kummer W. Galanin- and neuropeptide Y-like immunoreactivities coexist in paravertebral sympathetic neurones of the cat. Neurosci Lett. 1987; 78(2): 127-131, doi: 10.1016/03043940(87)90620-3, indexed in Pubmed: 2442671.

29. Majewski M, Kaleczyc J, Wasowicz K, et al. Characterization of afferent and efferent galanin-containing nerve fibres in the porcine ovary. Folia Histochem Cytobiol. 2002; 40(3): 261-268, indexed in Pubmed: 12219836.

30. Mclachlan EM. Autonomic Ganglia. Harwood Academic Publisher, Luxembourg 1995: 13-73.

31. Kummer W, Heym C. Neuropeptide distribution in the cervico-thoracic paravertebral ganglia of the cat with particular reference to calcitonin gene-related peptide immunoreactivity. Cell Tissue Res. 1988; 252(2): 463-471, doi: 10.1007/ /bf00214390, indexed in Pubmed: 2898295.
32. Schmitt M, Kummer W, Heym C. Calcitonin gene-related peptide (CGRP)-immunoreactive neurons in the human cervico-thoracic paravertebral ganglia. J Chem Neuroanat. 1988; 1(5): 287-292, indexed in Pubmed: 3267347.

33. Majewski M, Kummer W, Lakomy M, et al. Peptidaustattung aminerger and nicht-aminerger neuronaler elemente im ganglion stellatum des schweins. Verh Anat Ges. 1991; 170: $725-726$.

34. Nourinezhad J, Gilanpour H, Radmehr B. Prenatal development of the fetal thoracic sympathetic trunk in sheep (Ovis aries). Auton Neurosci. 2013; 177(2): 154-162, doi: 10.1016/j. autneu.2013.03.013, indexed in Pubmed: 23639816.

35. KuntzA. Components of splanchnic and intermesenteric nerves. J Comp Neurol. 1956; 105(2): 251-268, doi: 10.1002/ /cne. 901050205 .

Submitted: 28 August, 2017

Accepted after reviews: 9 December, 2017 Available as AoP: 20 December, 2017 
